\title{
El Pódcast: un Medio Y UNA FORMA DE COMUNICACIÓN
}

\author{
The Podcast: A Media And A Form Of Comunication
}

Carlos Saussure Figueroa Portilla ${ }^{1}$

\section{RESUMEN}

\begin{abstract}
El auge de los dispositivos tecnológicos móviles como el smrtphone ha permitido el impulso de medios de comunicación emergentes como el pódcast. El pódcast es un programa con una estructura similar a la radial, en el que se abordan temas diversos desde política, historia, economía, entre otros, hasta entretenimiento, cine, series de tv, etc. Aunque su crecimiento económico no es el esperado, su popularidad ha ido creciendo con el pasar de los años. Este ensayo repasa la evolución del pódcast como medio de comunicación, el desarrollo del pódcast en España y su contraste con el ámbito peruano; finalmente, se aborda su aplicación como herramienta informativa y educativa.
\end{abstract}

Palabras clave: pódcast, podcasting, medio de comunicación, educación.

\section{ABSTRACT}

The popularity and improvement of mobile devices as smartphone have permitted the growth of emergent media communication as the podcast. The podcast is a program like to a radio one where panelists (named podcasters) talk about different topics from politics, history, economy, among others, until entertainment, movie, theater, TV show, etc. Although its economic grow is not as predicted, its popularity has grown over the years. This essay reviews the evolution of podcast as a media, the development of podcast in Spain and its contrast with the Peruvian case; finally, its application as an informative and educational tool.

Key words: podcast, podcasting, media, education.

a comunicación es un acto innato en el ser humano, la posibilidad de compartir ideas y discutirlas favorece

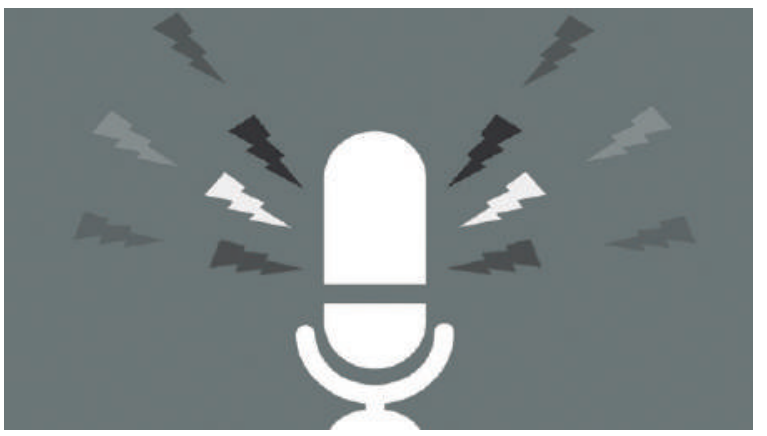

Modificado de: https:/ / www.reasonwhy.es/actualidad / indexar-podcast-busqueda-google-2019

que se exprese; de esta forma se transmite información y conocimiento. El arte rupestre comunicaba por medio de pinturas en cuevas algunos sucesos experimentados por antiguos habitantes, los egipcios comunicaban su cultura por medio de jeroglifos, los romanos registraban por escrito todo cuanto les parecía importante de recopilar (su propia historia, sobre todo), algunos otros pueblos comparten su historia por medio de narraciones orales y, así, se podría seguir dando ejemplos del acto comunicativo en diversos momentos de la historia de la humanidad. Con la aparición de

1 Magister en Innovación e Integración de las TIC en Educación (Pontificia Universidad Católica del Perú), Licenciado en Educación (Universidad Católica Sedes Sapientiae), docente universitario y pódcaster peruano. 
los medios de comunicación masivos, como la radio y la televisión, se logró transmitir información casi al instante. Todos podíamos tener una radio, encenderla e informarnos de inmediato de las noticias más importantes. Con el paso del tiempo, la televisión acaparó parte de los escuchas de radio, los que se adaptaron al nuevo formato. La información emitida por los medios de comunicación masivos, como la radio y la televisión, pasan por un filtro, tanto de audiencia como de la misma empresa emisora, lo cual frena el acceso a la información en plenitud, dirige la opinión a la línea editorial de la empresa emisora y limita la percepción de una realidad más completa. Y aunque tanto las emisoras de radio como las televisoras dan cierta cabida para que los oyentes o televidentes expresen su opinión, esta siempre está limitada en cuanto al tiempo que se dispone para el público. Con la aparición del primer smartphone en 2008, por iniciativa de Apple, la mejora de la conectividad móvil y el, cada vez mayor, acceso a internet por parte de la ciudadanía tanto urbana como rural, las posibilidades de comunicar se han incrementado. Pasamos de ser consumidores limitados de observar o escuchar, a ser productores constantes de información. Redes sociales como Facebook, Twitter o Instagram dan la posibilidad de informar y compartir experiencias en todo momento y en todo lugar. Si antes los primeros humanos tenían que conseguir tintes e ir a las cuevas para comunicar los hechos más saltantes de su día a día, ahora nosotros solo necesitamos un celular y conexión a internet. Los nuevos medios dieron paso a la evolución de la televisión con Youtube y con los servicios de streaming como Netflix.

La radio, por su parte, ha seguido un proceso distinto queha dado origen a lo que actualmente conocemos como pódcast. Este medio de comunicación puede referirse a un archivo de audio almacenado en una plataforma repositoria a la cual podemos suscribirnos para descargar automáticamente los archivos de audio. El pódcast puede ser también un programa con un formato similar al radial, que aborda temas específicos relacionados a humanidades, ciencias, entretenimiento, religión... propuestos por los productores y que se distribuye en formado de archivo de audio y que se almacena en una plataforma repositorio. Un pódcast es también el episodio de un programa que se almacena en formato de audio en una plataforma repositorio como Spotify, iVoox, Apple Podcast, Spreaker, etc. En palabras de Román \& Solano (2012, p. 58), el pódcast es «un archivo o una serie de archivos de audio o vídeo digital, previamente grabados, que pueden ser distribuidos por internet, y descargados automáticamente en un dispositivo portátil». Para comprender la presencia del pódcast como heredero natural de la radio, debemos tener en cuenta el proceso evolutivo que tuvo este medio digital. García (2016, p. 43) identifica cinco fases en este proceso: la fase predigital, la llegada de la radio a la web, el desarrollo de la radio digital, el aumento de la interactividad y la sindicación, momento en el que nace el podcasting tal y como es en la actualidad. (Ver Figura 1.)

Así mismo, se deben considerar las fases que comprenden el proceso de evolución de este medio de comunicación. García (2018, p. 186) propone que existen cuatro etapas que demarcan la evolución del pódcast. Si bien esta propuesta se enmarca en un contexto español, no deja de ser relevante hacer una comparación con el contexto peruano.

Según García (ídem), la primera etapa, que abarca los años 2004 al 2005, estuvo caracterizada por los primeros experimentos y experiencias de grabación de audio en Estados Unidos. En esta etapa nacen los pequeños 


\begin{tabular}{|l|l|l|l|}
\hline & 1 & Predigital & Radio exclusivamente hertziana \\
\cline { 2 - 4 } & 2 & Llegada a la web & Las emisoras usan internet como repetidor digital vía streaming \\
\cline { 2 - 4 } & 3 & Desarrollo de la radio digital & $\begin{array}{l}\text { Los portales web empiezan a insertar imágenes, infografías, opciones } \\
\text { para comentar. Nace la radio exclusivamente digital. }\end{array}$ \\
\cline { 2 - 4 } & 4 & Aumento de la interactividad & $\begin{array}{l}\text { Se empieza a empaquetar programas, es decir, las radios graban sus } \\
\text { programas y los suben a la red para que la gente pueda escucharlos } \\
\text { en diferido, con lo que se permite la descarga y su posterior escucha } \\
\text { aśncrona. El usuario puede elegir el programa que desee de un menú de } \\
\text { programación, según sus gustos e intereses (radio «a la carta»). }\end{array}$ \\
\cline { 2 - 5 } & 5 & Sindicación & $\begin{array}{l}\text { Se introduce la descarga automatizada de programas para su escucha } \\
\text { offline mediante motores RSS. Aparece el podcasting. }\end{array}$ \\
\hline
\end{tabular}

Figura 1. Adaptado de García (2016, p. 43)

grupos de escuchas, no existen aplicaciones para alojar pódcast y por lo general los creadores de pódcast (podcasters) alojan sus programas en blogs o webs propios.

En la segunda etapa, que se comprende entre los años 2006 al 2010, tanto la comunidad de escuchas y podcasters españoles crece. En mayo del 2006 se lleva a cabo la primera JPOD (Jornadas de Podcasting) en Málaga. Por otro lado, en Estados Unidos, importantes medios empiezan a abrir canales de pódcast, lo que aumenta el número de escuchas y de usuarios. Según The Podcast Consumer (2019), actualmente más de 140 millones de estadounidenses mayores de 12 años escuchan pódcast.

En la tercera etapa, que abarca los años 2010 al 2015, los medios de comunicación dirigen más la mirada hacia los pódcast de tal forma que los medios radiales empiezan a desarrollar sus propias iniciativas de pódcast a la par de sus programas convencionales. Se crea, en España, la Asociación Nacional de Podcasting. En Estados Unidos, el pódcast pasa de ser un medio amateur de autoproducción y autofinanciado a intentar convertirse en un medio de comunicación de masas similar a la radio, por lo que algunos programas famosos de radio pasan a convertirse en pódcast cuyo sustento se soporta en el crowdfounding o micromecenazgo por donaciones de los escuchas o fans.

La cuarta etapa, considerada a partir del 2015, demarca la aparición de pódcast a gran escala. En España se crea Podium Podcast, la primera red de pódcast creados bajo una misma marca, lo que da pie a nuevas iniciativas similares en ese país.

Como se aprecia, España ya tiene un proceso de desarrollo avanzado respecto al pódcast, mientras que en el caso peruano, la situación es distinta: Perú se encuentra en una marcada segunda etapa, en la que empiezan a coexistir iniciativas de pódcast por parte de grandes corporaciones de comunicación como RPP, La República, El Comercio, entre otros, con otras propuestas independientes en las que predomina el formato conversación, donde los temas que se abordan pueden ir desde coyuntura y política nacional, hasta películas y series del momento.

En la actualidad, resulta cada vez más sencillo acceder a un pódcast: plataformas como iTunes, iVoox (la plataforma más importante 
de pódcast en español) y Spotify permiten que el productor pueda alojar sus programas en distintos repositorios, lo que favorece una mayor visibilidad $\mathrm{y}$, por consiguiente, mayor probabilidad de aumentar escuchas; sin embargo, pese al tiempo de desarrollo que tiene el pódcast como medio de comunicación de nivel mundial, aún no logra despegar como una industria económicamente rentable. El 9 de mayo del 2016, aproximadamente 12 años después de la creación del pódcast, el diario El País de España publicó una nota que titulaba «Del pódcast no vive nadie», en respuesta a los fallidos pronósticos que indicaban que, para la fecha, la industria del pódcast debía facturar cerca de 400 millones de dólares.

Pese a las estadísticas económicas desfavorables, el pódcast a nivel mundial sigue creciendo, con iniciativas como las Jornadas de Pódcasts (España), el Maratón podcastero y el Interpodcast que se realiza cada año entre diversos pódcast de Iberoamérica y que consiste en que, por solo un episodio, un pódcast busca simular ser otro pódcast que se le asigna por sorteo, de tal forma que se sigue la misma estructura y temática del pódcast asignado, hasta incluso imitar a sus conductores. Estas iniciativas, además de permitir ampliar el número de escuchas, resultan un recurso importante para crear una comunidad colaborativa y cooperativa de podcasters que se retroalimenta de experiencias diversas.

Respecto de la utilidad del pódcast, las opciones van desde ser una herramienta de ocio hasta constituirse en una herramienta educativa. En un pódcast se pueden abordar temas de cultura popular y temas con fines educativos, como la historia, las ciencias y las letras. Por ejemplo, un docente, luego de cada sesión de clase, puede grabar un pódcast en formato «píldoras de aprendizaje» en el que resalten los puntos importantes de la clase, lo que brinda, al estudiante, una herramienta para reforzar el aprendizaje. Finalmente, cabe resaltar que el pódcast, además de ser un medio de comunicación, es también una forma de comunicación, que permite que el creador se exprese en libertad abordando los temas que le interesan. El problema de que los pódcast crezcan económicamente es que esto podría generar que grandes empresas se enfoquen en los pódcast más escuchados e inviertan dinero para parcializar el discurso de los podcasters; ante esto, la mejor alternativa es el aporte voluntario de los mismos escuchas o, como se señaló líneas arriba: crowdfounding o micromecenazgo.

\section{CONCLusiones}

El pódcast es una herramienta que tiene casi 15 años de creación y, aunque la audiencia ha crecido, aún no se convierte en el medio de masas que pronosticaron que sería. En el caso peruano, a partir del 2018, el pódcast ha empezado a ganar popularidad entre los grandes medios de comunicación y los productores independientes, lo que ha generado una mayor oferta de pódcast en el país; sin embargo, aún las escuchas son bajas como lo demuestra el estudio realizado por Audio.ad (2018) en el que se señala que solo el $20 \%$ de los encuestados escucha pódcast, frente al $60 \%$ que escucha audio digital en general (música, audiolibros, etc.).

Respecto de los usos, el pódcast resulta muy versátil en cuanto herramienta de comunicación, puesto que permite abordar temáticas que difícilmente son tocadas en medios de comunicación masiva y cubre un nicho de público interesado (escuchas) en tales temáticas. Este número de escuchas puede parecer irrisorio si se compara con ese $60 \%$ de usuarios de audio digital; sin embargo, debido 
a que el pódcast aborda temas muy específicos, se puede afirmar que son usuarios plenamente interesados en la propuesta, por tanto, es como si se tuviera una sala de conferencias llena de personas interesadas en la exposición. A esto hay que agregar que existen temáticas de pódcast tan distintas como gustos tienen las personas.

En el ámbito educativo, el uso del pódcast puede ser variado. Algunas propuestas, como la de Hargett (2017), hacen uso del pódcast comercial (pódcast producido con fines netamente informativos), cuyo contenido muchas veces presenta información relacionada con las ciencias de la salud, en este caso asociada a la enfermería. Por otra parte, los resultados expuestos por Piñón \& Manríquez (2017, pp. 7-8) muestran que el uso y desarrollo de pódcast como herramienta de aprendizaje en el curso de Comunicación incrementa considerablemente las habilidades lectoras y verbales del grupo con el cual se aplica la herramienta.

\section{Listado de algunos pódcast de habla hispana}

- Historia: Por las rutas de la curiosidad (Perú), La tertulia pódcast (Uruguay), Primun Gradus, La contrahistoria, Histocast (España).
- Ciencia: Leucocitos isotópicos (Ecuador), Coffee breack: señal y ruido (España)

- Comunicación: Manual de ortografía (España), La casa de palabras (Perú)

- Periodístico o documental: Convoca Radio (Perú), Radio Ambulante (pódcast pionero en español).

- Entretenimiento: Langoy Pódcast, Hablemos con Spoilers, Wilson Pódcast (Perú)

\section{Referencias Bibliográficas}

1. Abad, JM. Del pódcast no vive nadie. El País. URL disponible en: https://elpais.com/economia/2016/05/06/ actualidad /1462529204_717336.html

2. Audio.Ad. Audio digital 2018 en Perú (2). URL disponible en: http://www.audio.ad/landing-pages/ estudiodeaudiodigitalperu2018.html

3. Edison Research. The Podcast Consumer (6). URL disponible en: https: / / www.edisonresearch.com/the-pódcast-consumer2019/

4. García-Marín, D. Podcasting y transmedia: el transcasting. Tesis de Máster. Universidad Nacional de Educación a Distancia, España, 2016.

5. García-Marín, D. La radio en pijama. Origen, evolución y ecosistema del podcasting en español. Estudios sobre el mensaje periodístico. 2019; 25(1), 181-196.

6. Hargett, J. Podcasting in nursing education: using commercially prepared pódcast to spark learning. Teaching and learning in nursing. 2017;13:55-57.

7. Piñón, M \& Manríquez, M. Pódcast para el desarrollo de habilidades lectores y verbales. En J. Ruiz, J. Sánchez, \& E. Sánchez, Innovación docente y uso de las TIC en educación. Málaga: UMA Editorial; 2017.

8. Román, P \& Solano, I. Sistemas de audio y video por internet. Del streaming al webcast. En I. Solano, Pódcast educativo (págs. 55-74). Bogotá: Editorial MAD; 2012. 